\title{
Diagnostic Values of Serum Levels of Pepsinogens and Gastrin-17 for Screening Gastritis and Gastric Cancer in a High Risk Area in Northern Iran
}

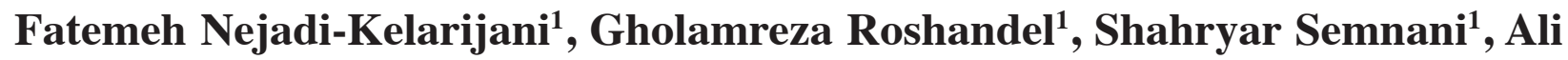 \\ Ahmadi $^{2}$, Behzad Faghani², Sima Besharat ${ }^{1}$, Atefeh Akhavan-Tabib ${ }^{1}$, Taghi \\ Amiriani $^{1 *}$
}

\begin{abstract}
Background: Gastric cancer (GC) is the second cause of cancer related death in the world. It may develop by progression from its precancerous condition, called gastric atrophy (GA) due to gastritis. The aim of this study was to evaluate the accuracy of serum levels of pepsinogens (Pg) and gastrin-17 (G17) as non-invasive methods to discriminate GA or GC (GA/GC) patients. Materials and Methods: Subjects referred to gastrointestinal clinics of Golestan province of Iran during 2010 and 2011 were invited to participate. Serum levels of PgI, PgII and G17 were measured using a GastroPanel kit. Based on the pathological examination of endoscopic biopsy samples, subjects were classified into four groups: normal, non-atrophic gastritis, GA, and GC. Receiver operating curve (ROC) analysis was used to determine cut-off values. Indices of validity were calculated for serum markers. Results: Study groups were normal individuals $(n=74)$, non-atrophic gastritis $(n=90), G A(n=31)$ and GC patients $(\mathrm{n}=30)$. The best cut-off points for PgI, PgI/II ratio, G17 and $\mathrm{HP}$ were $80 \mu \mathrm{g} / \mathrm{L}, 10,6 \mathrm{pmol} / \mathrm{L}$, and 20 EIU, respectively. PgI could differentiate GA/GC with high accuracy (AUC=0.83; 95\% CI: 0.76-0.89). The accuracy of a combination of PgI and PgI/II ratio for detecting GA/GC was also relatively high (AUC=0.78; 95\% CI: 0.70-0.86). Conclusions: Our findings suggested PgI alone as well as a combination of PgI and PgI/II ratio are valid markers to differentiate GA/GC. Therefore, Pgs may be considered in conducting GC screening programs in high-risk areas.
\end{abstract}

Keywords: Gastric cancer - pepsinogen - gastrin 17 - early detection - screening programs

Asian Pac J Cancer Prev, 15 (17), 7433-7436

\section{Introduction}

Gastric cancer (GC) is the second cause of cancer related death in the world and has a heterogenous geographic pattern of distribution (Vannella et al., 2012). Different factors have been proposed in the pathogenesis of GC including helicobacter pylori (HP) infection (Zheng et al., 2014), smoking (Zhong et al., 2012), diet (Lin et al., 2014) and family history (Mansour-Ghanaei et al., 2012). GC may develop by progression from its precancerous condition, called gastric atrophy (GA) (Kikuchi et al., 2011). Subjects with chronic GA are more susceptible to GC (Kikuchi et al., 2011; Vannella et al., 2012). So, diagnosis and treatment of this condition has a pivotal role in GC prevention. In addition, diagnosis and treatment of GC in early stages is very important in controlling this fatal disease, especially in high-risk areas. Endoscopic examination of the stomach is the method of choice for diagnosis GA and GC (Kikuchi et al., 2011; Rollan et al., 2006). But, it is an expensive and invasive method and may not be considered at population level. So, it has been proposed to find alternative non-invasive methods for early diagnosis or screening of these conditions.

Using serum biomarkers has been considered as potential screening method in this regards (Kikuchi et al., 2011). Pepsinogen enzyme (Pg), secreted from the gastric mucosa, has been suggested as a good non-invasive marker for diagnosis of corpus atrophic gastritis (Iijima et al., 2009; Kikuchi et al., 2011). Pg is classified into two main classes including PgI, which is solely secreted by fundic gland and PgII, which is secreted by pyloric glands and proximal duodenal mucosa.

Gastrin-17 (G17) is another possible biomarker for diagnosis GA. A negative relationship has been reported between serum level of G17 and the severity of gastritis especially in the antrum, because it is almost solely secreted by G-cells (Kikuchi et al., 2011).

Decrease in PgI, the ratio of PgI/PII and G17 may reflect the presence of abnormalities in gastric mucosa including atrophic gastritis and GC (Watabe et al., 2005; 
Oishi et al., 2006; Yanaoka et al., 2008; Kikuchi et al., 2011). Therefore, it is proposed that a combination of $\mathrm{Pg}$ and G17 may be helpful for diagnosis of atrophic gastritis and GC and consequently may be considered to develop a GC screening program (Shiotani et al., 2005; Rollan et al., 2006; Cao et al., 2007).

Golestan province located in northeastern Iran has been known as a high risk area for upper gastrointestinal cancers (Roshandel et al., 2012). As other high-risk areas, controlling GC is an important health issue in this region. Finding a screening program for early diagnosis of GC and its precursor lesions may be considered as the most effective strategy for controlling this disease in Golestan province as well as other high-risk areas. This study was designed to evaluate the accuracy of serum levels of $\mathrm{Pg}$ and G17 as non-invasive screening methods for early diagnosis of GA and GC.

\section{Materials and Methods}

This cross-sectional study was done in Golestan province of Iran during 2010-2011. Individuals who referred to gastrointestinal clinics for endoscopic examination, were invited to participate in our study. The exclusion criteria included history of chemotherapy or gastric surgery, history of helicobacter pylori eradication, history of anti-coagulant therapy and serious systemic diseases including diabetes, liver cirrhosis, and chronic renal failure.

Ademographic questionnaire was completed including socio-demographic data and medical history. After obtaining informed consent, a fasting blood sample of 10 cc was taken. Serum was separated and frozen in $-20^{\circ} \mathrm{c}$ until use. Serum levels of PgI, PgII, G17 and HP antibody were measured using GastroPanel kit, Biohit, Finland. Endoscopic examination was done by gastroenterologists and biopsies were taken. Pathological examinations of biopsy samples were done by an expert pathologist and the results were reported according to the updated Sydney system (Dixon et al., 1996). Based on the pathological examination, subjects were classified into four groups including normal, non-atrophic gastritis, GA, and GC.

Data was entered into computer using SPSS-16 software and analyzed by chi-square, t-test and One-way ANOVA. Receiver operating curve (ROC) analysis was used to determine the cut-offs for PgI, PgI/II ratio, G17 and HP. Sensitivity and specificity of these markers to distinguish the above mentioned groups (non-atrophic gastritis, GA, and GC) were calculated. Positive predictive value (PPV), negative predictive value (NPV), area under curves (AUC) and the $95 \%$ confidence intervals (CI) were also calculated and presented. Finally, regarding the clinical importance of GA and GC, the data of subjects with the diagnosis of GA or GC was merged to generate a combined group called GA/GC. Indices of validity of serum markers to distinguish $\mathrm{GA} / \mathrm{GC}$ were also calculated. $\mathrm{P}$-values of less than 0.05 were considered significant.

This study was approved by the ethical committee of Golestan University of Medical Sciences.

\section{Results}

Totally, 234 subjects were recruited. The mean (SE) of participants' age was 48.5 (1.1) years. 115 (49.1\%) of participants were male with mean (SD) age of 50.3 (1.6) and the remaining were female with mean (SD) age of 46.8 (1.4) years $(\mathrm{p}=0.1)$. Study groups included normal individuals $(n=74)$, non-atrophic gastritis $(n=90)$, GA

Table 1. Demographic Characteristics and Serum Levels of Pepsinogen, Gastrin-17 and Helicobacter (HP) Antibody in Study Groups

\begin{tabular}{|c|c|c|c|c|c|}
\hline Gender & $\begin{array}{l}\text { Normal } \\
(n=74)\end{array}$ & $\begin{array}{c}\text { Non-atrophic } \\
\text { gastritis }(n=90)\end{array}$ & $\begin{array}{l}\text { Gastric } \\
\text { atrophy }(n=31)\end{array}$ & $\begin{array}{c}\text { Gastric } \\
\text { cancer }(n=39)\end{array}$ & $\mathrm{p}$ value \\
\hline Male, N (\%) & $38(51.4)$ & $49(54.4)$ & $17(54.8)$ & $15(38.5)$ & 0.38 \\
\hline Female, N (\%) & $36(48.6)$ & $41(45.6)$ & $14(45.2)$ & $24(61.5)$ & \\
\hline Age (years), mean $\pm S E$ & $44.27 \pm 1.9$ & $45.88 \pm 1.5$ & $51.52 \pm 2.5$ & $60.23 \pm 2.5$ & $<0.001$ \\
\hline Pepsinogen I $(\mu \mathrm{g} / \mathrm{L})$, mean $\pm \mathrm{SE}$ & $135.19 \pm 9.4$ & $96.94 \pm 5.4$ & $66.50 \pm 9.9$ & $51.40 \pm 5.8$ & $<0.001$ \\
\hline Pepsinogen II $(\mu \mathrm{g} / \mathrm{L})$, mean $\pm \mathrm{SE}$ & $18.00 \pm 2.1$ & $16.16 \pm 1.2$ & $13.85 \pm 1.7$ & $17.01 \pm 2.8$ & 0.59 \\
\hline Pepsinogen $\mathrm{I} / \mathrm{II}$ ratio, mean $\pm \mathrm{SE}$ & $12.49 \pm 1.5$ & $7.70 \pm 0.5$ & $6.03 \pm 1.2$ & $4.73 \pm 0.7$ & $<0.001$ \\
\hline Gastrin $17(\mathrm{pmol} / \mathrm{L})$, mean $\pm \mathrm{SE}$ & $13.56 \pm 2.1$ & $13.82 \pm 1.7$ & $8.32 \pm 1.6$ & $10.81 \pm 2.8$ & 0.34 \\
\hline HP antibody (EIU), mean \pm SE & $26.39 \pm 3.0$ & $55.20 \pm 2.7$ & $56.90 \pm 4.9$ & $46.43 \pm 4.4$ & $<0.001$ \\
\hline
\end{tabular}

Table 2. Indices of Validity for Serum Levels of Pepsinogen I (PgI), PgI/II Ratio and Gastrin-17 (G17) to Distinguish Non-Atrophic Gastritis, Gastric Atrophy and Gastric Cancer

\begin{tabular}{|c|c|c|c|c|}
\hline & & Sensitivity & Specificity & Area Under ROC curve \\
\hline \multirow[t]{3}{*}{ Non-atrophic gastritis } & $\mathrm{PgI}<80 \mu \mathrm{g} / \mathrm{l}$ & $47.7(37.7-58.2)$ & $72.6(62.4-82.8)$ & $0.57(0.43-0.70)$ \\
\hline & $\mathrm{PgI} / \mathrm{II}$ ratio $<10$ & $77.3(68.5-86.0)$ & $38.0(26.7-49.3)$ & $0.59(0.45-0.72)$ \\
\hline & $\mathrm{G} 17<6 \mathrm{pmol} / 1$ & $45.6(35.3-55.8)$ & $47.9(36.5-59.4)$ & $0.46(0.33-0.60)$ \\
\hline \multirow[t]{3}{*}{ Atrophic gastritis } & $\mathrm{PgI}<80 \mu \mathrm{g} / \mathrm{l}$ & $77.4(62.7-92.1)$ & $72.6(62.4-82.8)$ & $0.80(0.71-0.89)$ \\
\hline & $\mathrm{PgI} / \mathrm{II}$ ratio $<10$ & $90.3(79.9-1.0)$ & $38.0(26.7-49.3)$ & $0.74(0.65-0.84)$ \\
\hline & $\mathrm{G} 17<6 \mathrm{pmol} / 1$ & $64.5(47.7-81.4)$ & $47.9(36.5-59.4)$ & $0.56(0.45-0.66)$ \\
\hline \multirow[t]{3}{*}{ Gastric cancer } & $\mathrm{PgI}<80 \mu \mathrm{g} / \mathrm{l}$ & $87.2(76.7-97.7)$ & $72.6(62.4-82.8)$ & $0.85(0.78-0.92)$ \\
\hline & $\mathrm{PgI} / \mathrm{II}$ ratio $<10$ & $92.3(83.9-1.0)$ & $38.0(26.7-49.3)$ & $0.79(0.70-0.87)$ \\
\hline & $\mathrm{G} 17<6 \mathrm{pmol} / 1$ & $43.6(28.0-59.2)$ & $47.9(36.5-59.4)$ & $0.51(0.40-0.62)$ \\
\hline
\end{tabular}


Table 3. Indices of Validity for Serum Levels of Pepsinogen I (PgI), PgI/II Ratio and Gastrin-17 (G17) and their Combinations to Distinguish Gastric Atrophy or Gastric Cancer

\begin{tabular}{lccccc}
\hline & Sensitivity & Specificity & PPV & NPV & AUC \\
\hline $\mathrm{PgI}<80 \mu \mathrm{g} / \mathrm{l}$ & $82.9(74.0-91.7)$ & $72.6(62.4-82.8)$ & 74.4 & 81.5 & $0.83(0.76-0.89)$ \\
$\mathrm{PgI}<80 \mu \mathrm{g} / \mathrm{l} \mathrm{AND} \mathrm{PgI/II} \mathrm{ratio<10}$ & $80.0(70.6-89.4)$ & $76.1(66.1-86.0)$ & 76.7 & 79.4 & $0.78(0.70-0.86)$ \\
$\mathrm{PgI} / \mathrm{II} \mathrm{ratio}<10$ & $91.4(84.9-98.0)$ & $38.0(26.7-49.3)$ & 59.3 & 81.8 & $0.76(0.69-0.84)$ \\
$\mathrm{G} 17<6$ & $52.9(41.2-64.6)$ & $47.9(36.5-59.4)$ & 49.3 & 51.5 & $0.53(0.43-0.62)$ \\
$\mathrm{PgI}<80 \mu \mathrm{g} / \mathrm{l} \mathrm{AND} \mathrm{G17<6} \mathrm{pmol} / 1$ & $42.9(31.3-54.5)$ & $83.3(74.7-91.9)$ & 71.4 & 60 & $0.63(0.54-0.72)$ \\
$\mathrm{PgI}<80 \mu \mathrm{g} / \mathrm{l} \mathrm{OR} \mathrm{G17<6} \mathrm{pmol} / \mathrm{l}$ & $92.9(86.8-98.9)$ & $36.1(25.0-47.2)$ & 58.6 & 83.9 & $0.65(0.55-0.74)$ \\
$\mathrm{PgI} / \mathrm{II} \mathrm{ratio}<10 \mathrm{AND} \mathrm{G17}<6 \mathrm{pmol} / \mathrm{l}$ & $50.0(38.3-61.7)$ & $73.2(62.9-83.5)$ & 64.8 & 59.8 & $0.62(0.52-0.71)$ \\
$\mathrm{PgI} / \mathrm{II} \mathrm{ratio}<10$ OR G17<6 pmol/1 & $94.3(88.8-99.7)$ & $12.7(4.9-20.4)$ & 51.6 & 69.2 & $0.54(0.44-0.63)$ \\
\hline
\end{tabular}

$(n=31)$ and GC $(n=30)$. Table 1 shows the characteristics of the study groups. The age was significantly higher in GC and atrophic gastritis groups than other ones. No significant difference was found in the level of PgI between GC and GA groups ( $p$-value $=0.3$ ). The differences in serum levels of PgI between other groups were statistically significant. The serum levels of PgI/II ratio and HP antibody were significantly higher and lower, respectively in normal subjects than other groups.

The best cut-off points for $\mathrm{PgI}, \mathrm{PgI} / \mathrm{II}$ ratio, G17 and HP were $80 \mu \mathrm{g} / \mathrm{L}, 10,6 \mathrm{pmol} / \mathrm{L}$, and $20 \mathrm{EIU}$, respectively. The proportion of HP positivity was significantly lower in normal subjects $(41.9 \%)$ than those with GC $(87.2 \%), \mathrm{GA}(90.3 \%)$ and non-atrophic gastritis $(91.1 \%)$ (p-value $<0.001$ ). Table 2 shows the sensitivity, specificity and AUC of PgI, PgI/II ratio and G17 to distinguish non-atrophic gastritis, GA and GC. Indices of validity for each of the above-mentioned markers as well as their combinations to discriminate GA/GC patients are shown in table 3 .

\section{Discussion}

The aim of this study was to evaluate the accuracy of serum levels of $\mathrm{Pg}$ and G17 as non-invasive screening methods for GC. Regarding the clinical importance of GA and GC, we mainly focused on assessing indices of validity of these markers to distinguish GA/GC patients.

The results of this study showed that $\mathrm{PgI}$ could differentiate GA/GC with a high accuracy (AUC $=0.83$ ). The accuracy of a combination of $\mathrm{PgI}$ and $\mathrm{PgI} / \mathrm{II}$ ratio for detecting $\mathrm{GA} / \mathrm{GC}$ was also relatively high $(\mathrm{AUC}=0.78)$.

High accuracy for $\mathrm{Pgs}$ was reported for discriminating GA or GC in a number of previous studies. The results of a study from Portugal showed a sensitivity of $67 \%$ and a specificity of $47 \%$ for Pg for early detection of GC (Lomba-Viana et al., 2012). Cao et al found a high AUC (0.88) for PgI in patients with GA (Cao et al., 2007). Nasrollahzadeh et al (2011) similarly reported relatively high accuracy $(\mathrm{AUC}=0.78$ ) for $\mathrm{PgI}$ as well as for the combination of $\mathrm{PgI}$ and $\mathrm{PgI} / \mathrm{II}$ ratio $(\mathrm{AUC}=0.79)$ for diagnosis GA. Shikata et al (2012) reported a sensitivity and specificity of $71.0 \%$ and $69.2 \%$ for a combination of $\mathrm{PgI}$ and $\mathrm{PgI} / \mathrm{II}$ ratio to discriminate GC. Miki et al (2003) reported a sensitivity of $80 \%$ and a specificity of $70 \%$ for the combination of $\mathrm{PgI}$ and $\mathrm{PgI} / \mathrm{II}$ ratio to detect GC. According to the results of a study by kitahara et al (1999), the sensitivity and specificity of this combination to distinguish GC were $84.6 \%$ and $73.5 \%$, respectively.

Therefore, PgI as well as a combination of PgI and $\mathrm{PgI} / \mathrm{II}$ ratio may be considered as valid biomarkers for discriminating GA/GC. Regarding the clinical importance of GA and GC, detection of these conditions is the main aim of conducting screening programs. Therefore, PgI alone or a combination of PgI and PgI/II ration may be used in gastric cancer screening programs especially in high-risk areas. This may result in detection of precancerous lesions or early gastric cancers and finally may improve patients' quality of life.

According to our findings, the accuracy of $\mathrm{PgI}$ alone was higher than its combination with $\mathrm{PgI} / \mathrm{II}$ ratio. But, considering the pathophysiology of GA (Miki et al., 1993; Miki et al., 1987), the combination of PgI and PgI/II ratio may reflect a more accurate picture of the mucosal status in the stomach. Therefore, these points should be taken into consideration for conducting gastric cancer screening program in our area as well as other similar population.

Our results did not suggest G17 alone as well as its combinations with Pgs as good biomarker for diagnosis of GA/GC. We also found no significant difference in serum levels of G17 between study groups. Shafaghi et al (2013) reported a low AUC (59\%) for G17 for detecting GA. Cao et al similarly reported no significant difference in the serum levels of G17 between patients with GA and normal subjects (Cao et al., 2007). But, the results of some previous studies showed relatively high accuracy for G17 to differentiate GA or GC. Nasrollahzadeh et al (2011) reported an AUC of 0.77 for G17 to discriminate GA. Kikushi et al (2011) also suggested G17 as good biomarker for diagnosis GA. Regarding the role of G17 pathogenesis of GC (Copps et al., 2009), further studies are warranted to assess the validity of G17 to differentiate GA/GC.

According to our findings, pepsinogens and G17 were not enough valid to differentiate non-atrophic gastritis. Nasrollahzadeh et al (2011) similarly reported a relatively low validity for Pgs and G17 to distinguish non-atrophic gastritis. Non-atrophic gastritis is not a clinically important pathology. In other words, there is no further evaluation for subjects diagnosed as non-atrophic gastritis. Therefore, detecting non-atrophic gastritis may not be an important goal in GC screening programs.

We found a significant higher frequency of $\mathrm{HP}$ positivity in patients with GC, GA and non-atrophic gastritis. The association of HP infection with GC and GA has been known, previously (Adamu et al., 2011; Correa, 1992). Ghasemi-Kebria et al (2011) reported high 
prevalence of HP infection in our area. Therefore, it is recommended to consider HP infection for conducting GC controlling programs (e.g. screening) in Golestan province of Iran as well as other high-risk areas.

In conclusion, our results suggested $\mathrm{PgI}$ alone and a combination of $\mathrm{PgI}$ and $\mathrm{PgI} / \mathrm{II}$ ratio as valid markers to differentiate GA/GC. Therefore, Pgs may be considered in conducting GC screening programs in high-risk areas.

\section{Acknowledgements}

We would like to thank gastroenterologists as well as the staff of the gastrointestinal clinics in Golestan province for their collaborations in sample and data collection.

\section{References}

Adamu MA, Weck MN, Rothenbacher D, Brenner H (2011). Incidence and risk factors for the development of chronic atrophic gastritis: five year follow-up of a population-based cohort study. Int J Cancer, 128, 1652-8.

Cao Q, Ran ZH, Xiao SD (2007). Screening of atrophic gastritis and gastric cancer by serum pepsinogen, gastrin 17 and Helicobacter pylori immunoglobulin G antibodies. J Dig Dis, 8, 15-22.

Copps J, Murphy RF, Lovas S (2009). The production and role of gastrin-17 and gastrin-17-gly in gastrointestinal cancers. Protein Pept Lett, 16, 1504.

Correa P (1992). Human gastric carcinogenesis: a multistep and multifactorial process--first american cancer society award lecture on cancer epidemiology and prevention. Cancer Res, 52, 6735-40.

Dixon MF, Genta RM, Yardley JH, Correa P(1996). Classification and grading of gastritis. the updated sydney system. international workshop on the histopathology of gastritis, houston 1994. Am J Surg Pathol, 20, 1161-81.

Ghasemi Kebria F, Bagheri H, Semnani S, Ghaemi E (2011). Seroprevalence of anti-Hp and anti-cagA antibodies among healthy persons in Golestan province, northeast of Iran (2010). Caspian J Intern Med, 2, 256-60.

Iijima K, Abe Y, Kikuchi R, et al (2009). Serum biomarker tests are useful in delineating between patients with gastric atrophy and normal, healthy stomach. World J Gastroenterol, 15, 853-9.

Kikuchi R, Abe Y, Iijima K, et al (2011). Low serum levels of pepsinogen and gastrin 17 are predictive of extensive gastric atrophy with high-risk of early gastric cancer. Tohoku J Exp Med, 223, 35-44.

Kitahara F, Kobayashi K, Sato T, et al (1999). Accuracy of screening for gastric cancer using serum pepsinogen concentrations. Gut, 44, 693-7.

Lin SH, Li YH, Leung K, Huang CY, Wang XR (2014). Salt processed food and gastric cancer in a Chinese population. Asian Pac J Cancer Prev, 15, 5293-8.

Lomba-Viana R, Dinis-Ribeiro M, Fonseca F, Vieira AS, et al (2012). Serum pepsinogen test for early detection of gastric cancer in a European country. Eur J Gastroenterol Hepatol, 24, 37-41.

Mansour-Ghanaei F, Joukar F, Baghaei SM, et al (2012). Gastric precancerous lesions in first degree relatives of patients with known gastric cancer: a cross-sectional prospective study in Guilan Province, north of Iran. Asian Pac J Cancer Prev, 13, 1779-82.

Miki K, Ichinose M, Ishikawa KB, et al (1993). Clinical application of serum pepsinogen I and II levels for mass screening to detect gastric cancer. Jpn J Cancer Res, 84, 1086-90.

Miki K, Ichinose M, Shimizu A, et al (1987). Serum pepsinogens as a screening test of extensive chronic gastritis. Gastroenterol Jpn, 22, 133-41.

Miki K, Morita M, Sasajima M, et al (2003). Usefulness of gastric cancer screening using the serum pepsinogen test method. Am J Gastroenterol, 98, 735-9.

Nasrollahzadeh D, Aghcheli K, Sotoudeh M, et al (2011). Accuracy and cut-off values of pepsinogens $\mathrm{i}$, ii and gastrin 17 for diagnosis of gastric fundic atrophy: influence of gastritis. PLoS One, 6, 26957.

Oishi Y, Kiyohara Y, Kubo M, et al (2006). The serum pepsinogen test as a predictor of gastric cancer. Am $J$ Epidemiol, 163, 629-37.

Rollan A, Ferreccio C, Gederlini A, Serrano C, Torres J, Harris P (2006). Non-invasive diagnosis of gastric mucosal atrophy in an asymptomatic population with high prevalence of gastric cancer. World J Gastroenterol, 12, 7172-8.

Roshandel G, Sadjadi A, Aarabi M, et al (2012). Cancer Incidence in Golestan Province: Report of an Ongoing Population-based Cancer Registry in Iran between 2004 and 2008. Arch Iran Med, 15, 196-200.

Shafaghi A, Mansour-Ghanaei F, Joukar F, et al (2013). Serum gastrin and the pepsinogen I/II ratio as markers for diagnosis of premalignant gastric lesions. Asian Pac J Cancer Prev, 14, 3931-6.

Shikata K, Ninomiya T, Yonemoto K, et al (2012). Optimal cutoff value of the serum pepsinogen level for prediction of gastric cancer incidence: the Hisayama Study. Scand $J$ Gastroenterol, 47, 669-75.

Shiotani A, Iishi H, Uedo N, et al (2005). Histologic and serum risk markers for noncardia early gastric cancer. Int J Cancer, 115, 463-9.

Vannella L, Lahner E, Annibale B (2012). Risk for gastric neoplasias in patients with chronic atrophic gastritis: A critical reappraisal. World J Gastroenterol, 18, 1279-85.

Watabe H, Mitsushima T, Yamaji Y, et al (2005). Predicting the development of gastric cancer from combining Helicobacter pylori antibodies and serum pepsinogen status: a prospective endoscopic cohort study. Gut, 54, 764-8.

Yanaoka K, Oka M, Mukoubayashi C, et al (2008). Cancer highrisk subjects identified by serum pepsinogen tests: outcomes after 10-year follow-up in asymptomatic middle-aged males. Cancer Epidemiol Biomarkers Prev, 17, 838-45.

Zheng RN, Li SR, Masahiro A (2012). Helicobacter pylori CagA and gastric carcinogenesis. Asian Pac J Cancer Prev, 13, 6305-10.

Zhong C, Li KN, Bi JW, Wang BC (2012). Sodium intake, salt taste and gastric cancer risk according to Helicobacter pylori infection, smoking, histological type and tumor site in China. Asian Pac J Cancer Prev, 13, 2481-4. 